\title{
Temporal fluctuations of two Mediterranean salp populations from 1967 to 1990 . Analysis of the influence of environmental variables using a Markov chain model
}

\author{
F. Ménard ${ }^{1,2}$, S. Dallot ${ }^{2}$, G. Thomas ${ }^{1}$, J. C. Braconnot ${ }^{2}$ \\ ${ }^{1}$ Département de Biostatistique et Informatique Médicale, 1 av. Claude Vellefaux, F-75475 Paris Cedex 10, France \\ ${ }^{2}$ Station Zoologique, URA 716, Observatoire Océanologique, BP 28, F-06230 Villefranche-sur-Mer, France
}

\begin{abstract}
The weekly abundances of the sexual phase (aggregate zooid) of 2 salp populations (tunicates Thalia democratica and Salpa fusiformis) were determined from 1967 to 1990 at a fixed station. in the coastal waters of the Western Mediterranean, using a discrete scale of abundance. For both species, the abundance time series shows the occasional development of blooms of aggregate zooids. Several hydrological and meteorological variables were recorded concomitantly, and their influence on the occurrence of blooms was evaluated using a Markov regression model for ordinal time series. Abundance at Week $t$ was found to depend on the size of the population for the 2 previous weeks and on environmental variables. The influence of hydrological variables, air temperature and irradiance conesponds to the relationship between sedsonal stratification of the water column and occurence of blooms: the stronger the stratification, the lower the probability of observing high densities of salps. Wind stress was also found to exert a significant influence, with gusts of wind facilitating the development of blooms through the renewal of the pelagic production. The influence of easterly winds, which involves a process of surface waters accumulating near the coast, is limited to $T$. democratica. Conversely, the influence of westerly winds, which leads to local upwelling, is limited to S. fusiformis. These results are consistent with known differences in the spatial distribution of $T$. democratica and $S$. fusiformis with respect to both distance to the coast and depth.
\end{abstract}

KEY WORDS: Climate $\cdot$ Markov regression model $\cdot$ Ordinal time series $\cdot$ Salps $\cdot$ Zooplankton

\section{INTRODUCTION}

The pelagic tunicates Thalia democratica Forsskål, 1775 and Salpa fusiformis Cuvier, 1804 are the most common salps in the coastal waters of the Western Mediterranean. The life cycle of salps includes both a sexual and an asexual phase: the solitary asexual zooids release, by budding, several chains of aggregate sexual zooids. Solitary zooids and aggregate zooids are similar in size and in food requirements. In our laboratory, at 14 to $15^{\circ} \mathrm{C}$, and under saturated food conditions, the solitary zooids of both species may produce the first chain of aggregate zooids after a growth period of $6 \mathrm{~d}$ (Braconnot 1963, Braconnot et al. 1988). The chains are formed of 50 ( $T$. democratica) to more than 100 (S. fusiformis) aggregate zooids of similar length, and are repeatedly released every $2 \mathrm{~d}$. Within the young chains, each aggregate zooid acts as a fertile female, soon producing a unique solitary zooid which incubates for 5 or $6 \mathrm{~d}$ inside the body cavity. Later on, the aggregate zooids develop into males. Owing to their particular reproduction cycle, these gelatinous macrozooplanktonic filter feeders have one of the fastest growth rates among multicellular organisms (Heron \& Benham 1984, 1985, Le Borgne \& Moll 1986, Braconnot et al. 1988): under favourable conditions, a few individuals from both phases may give rise to blooms that are generally observed in spring or at the beginning of summer. Blooms of $T$. democratica and $S$. fusiformis have often been tracked on continental 
shelves of the world ocean during periods lasting days to months (e.g. Fraser 1962, Berner 1967, Brattström 1972, Atkinson et al. 1978, Madhupratap et al. 1980, Le Borgne 1983, Heron \& Benham 1984, Tsuda \& Nemoto 1992). The availability of large amounts of food appears to be one of the main factors allowing the development of a sustained salp population, and the role of the quality of phytoplankton (Silver 1975) and the level of its growth rate (Le Borgne 1983) has been recognised as critical. In the Georgia Bight (W Atlantic), Deibel (1985) showed that only salps and doliolids are capable of responding rapidly to shortlived phytoplankton blooms.

Because of their high filtration rates and the wide size range of the filtered particles, salps play a critical role in the consumption of phytoplankton (Deibel 1982. Mullin 1983, Madin \& Cetta 1984). In Mediterranean coastal waters, they are able to decrease the algal biomass, even during the spring phytoplankton bloom (Andersen 1985, Nival et al. 1985). Their production of large fecal pellets is responsible for a fast downwards transfer of organic matter in the marine ecosystem (Madin 1982, Morris et al. 1988, Caron et al. 1989). Despite the major impact of salps on primary production in marine ecosystems, and in comparison with other planktonic groups such as copepods, multiannual records of these species are few, and little is known about oceanographic factors involved in the emergence and decay of salp blooms.

This led us to analyse the fluctuations in abundance of Thalia democratica and Salpa fusiformis, which were sampled from 1967 to 1990 in the Bay of Villefranche-sur-Mer (Western Mediterranean). The principal aim was to assess the influence of hydrological and meteorological variables on the abundance levels of the 2 populations during the periods corresponding to the possible occurrence of blooms. During blooms, aggregate zooids represent about $95 \%$ of the whole salp population (Braconnot 1963), while sustained budding of new chains results in a low variability of the aggregate zooid to solitary zooid number ratio. During periods of low abundance, aggregate zooids still account for about $85 \%$ of salps. Moreover, both phases probably share the same regulatory environmental factors. Hereafter we use the generic term 'salps' although aggregate zooids only were enumerated. The sizes of the populations were determined weekly according to Frontier's (1969) semiquantitative scale of abundance classes, which has been shown to be well adapted to describe the spatial and temporal variations of zooplanktonic species at the classical regional scales used in oceanographic studies (Frontier 1969).

Because the observations are semiquantitative (ordinal), time series analysis techniques such as spectral analysis (Priestley 1989) or ARIMA models (Box \&
Jenkins 1976) cannot be used. A more natural and conceptually satisfying approach is based on the use of socalled Markov chain models. Such models have been used by Thompson \& Vertinsky (1975) for complex simulation models of birds foraging; by Usher (1979) for problems of ecological succession; and by Eston et al. (1986) to study spatial interactions between 2 species. Related methods are the transition matrix approach of Woolhouse \& Harmsen (1991), used to study the dynamics of an apple aphid, and the semiMarkov model of Munholland \& Kalbfleisch (1991), used to describe an insect's life history.

This study presents the application to the salp data of a Markov regression model for ordinal ecological series (Ménard et al. 1993), that can accommodate continuous and possibly time-dependent covariates. The model is used to assess the influence of environmental variables on the dynamics of salp abundance. Results are consistent with known biogeographical differences between Thalia democratica and Salpa fusiformis.

\section{MATERIALS AND METHODS}

Sampling and descriptors of salp abundance. The $B$ sampling station is located at the southern entrance of the Bay of Villefranche-sur-Mer $\left(43^{\circ} 41^{\prime} 10^{\prime \prime} \mathrm{N}, 7^{\circ} 19^{\prime}\right.$ $0^{\prime \prime} \mathrm{E}$ ) and has a maximal depth of $80 \mathrm{~m}$. This part of the Bay is open to the sea.

Salps were sampled at Station B by vertically towing a Juday Bogorov net from a depth of $75 \mathrm{~m}$ to the sea surface. This net has an opening diameter of $0.5 \mathrm{~m}$ a mesh of $330 \mu \mathrm{m}$ and a filtering length of $1.8 \mathrm{~m}$. The mean filtered volume of water was estimated using a Tsurimi flowmeter as about $10 \mathrm{~m}^{3}$ per haul. From November 1966 to December 1990, samples were taken at a maximum frequency of twice a day, except during weekends. Hauls from the same week were pooled, thus yielding a series of weekly samples. No data were available for $12.7 \%$ of the weeks. Salp abundance was determined according to a semiquantitative scale of abundance (Frontier 1969). The limits of the classes are approximately based upon a geometric progression with basis 4.3. Because of the differing numbers of hauls from week to week, the weekly abundance class was determined from the approximate number of salps in the pooled sample divided by the number of hauls in the corresponding week. As shown in Table 1, 8 classes were used for the enumeration of the samples. For example, if 5 hauls were obtained during a given week and the total number of zooids in the pooled sample fell between 90 and 400 , then the weekly abundance is coded as Class 4 .

Hydrological and meteorological variables. Seawater temperature $\left({ }^{\circ} \mathrm{C}\right.$ ), salinity (psu) and computed 
seawater density $\left(\mathrm{kg} \mathrm{m}^{-3}\right)$ at depths of $0,10,20,30,50$ and $75 \mathrm{~m}$, have been recorded at Station B since 1957 (Etienne et al. 1991). Because of irregular time spacing within weeks and missing observations, the data were smoothed by taking averages over $2 \mathrm{wk}$ periods.

Daily measures of air temperature $\left({ }^{\circ} \mathrm{C}\right)$, mean wind velocity considering all directions $\left(\mathrm{m} \mathrm{s}^{-1}\right)$, maximum wind velocity $\left(\mathrm{m} \mathrm{s}^{-1}\right.$ ) and direction were provided by the ground-based meteorological station 'Sémaphore du Cap Ferrat', which is located $800 \mathrm{~m}$ from the sampling station at an altitude of $138 \mathrm{~m}$. Daily light intensity (irradiance, $\mathrm{J} \mathrm{cm}^{-2}$ ) was measured at sea level at Nice airport (10 km from Station B), using a Kipp \& Zonen pyranometer. Except for wind characteristics, weekly means of these meteorological variables were used. The wind energy at sea surface level is a complex function of wind velocity, air density and an aerodynamic friction coefficient. Here, the square of wind velocity was used as a index of wind stress. However, meteorological records do not contain the duration of windy periods. Weekly indexes were thus computed as the sum of the daily velocities squared, considering days with mean velocity over $6 \mathrm{~m} \mathrm{~s}^{-1}$ (mean wind index) and maximum velocity over $10 \mathrm{~m} \mathrm{~s}^{-1}$ (maximum wind index). These thresholds were used because velocities lower than these values are not expected to exert a significant effect on the surface layer. Maximum wind was further categorised as westerly or easterly, to reflect the dominant patterns of the area.

The model. The statistical model is described in the Appendix and details may be found in Ménard et al. (1993). The idea is to specify the probability distribution of abundance at time $t$ as a function of abundances observed before $t$. Markov models correspond to the case when only a finite number of previous states influence the outcome at time $t$. This number is called the order of the process. Zero order corresponds to stochastic independence between successive observations, meaning that abundance in a given week does not depend on previous weeks' abundances. If the dependence is on the most recent prior abundance

Table 1. Definition of abundance classes according to Frontier (1969)

\begin{tabular}{|cc|}
\hline No. of salps per haul & Abundance class \\
\hline 0 & 1 \\
$1-3$ & 2 \\
$4-17$ & 3 \\
$18-80$ & 4 \\
$80-350$ & 5 \\
$350-1500$ & 6 \\
$1500-6500$ & 7 \\
$6500-27000$ & 8 \\
\hline
\end{tabular}

only, the process is of order 1, and the transition probability $\mathrm{P}_{i, j}$ is the probability that salp abundance changes from $i$ to $j$ over 1 period of time (here, $1 \mathrm{wk}$ ). With 5 categories, there is a total of $5^{2}$ transition probabilities to estimate. A second-order process is specified by $5^{3}$ transition probabilities of the form $\mathrm{P}_{k, i, j,}$ the probability of transition to abundance $j$ at time $t$, given that abundance was $k$ at time $t-2$, and $i$ at time $t-1$. Generally, a process with $S$ states and of order $o$ leads to $S^{o+1}$ transitions between categories. For the quantitative statistical analysis of the salp data, abundance Classes 5 to 8 were combined to form a single class, because of the small numbers of observations in Classes 6, 7 and 8 .

The environmental variables of interest are introduced as exogenous covariates in the functions specifying the transition probabilities. Only past values, say at time $t-\tau$, are considered, in order to permit a causal interpretation. $\tau$ is called the time lag. Thus, $\mathrm{P}_{k, i, j}(z)$ is the probability of transition from abundance category $k$ at time $t-2$ and $i$ at time $t-1$ to category $j$ at time $t$, when the value taken by the covariates of interest is $z$ at $t-\tau$.

Parameters of the model and their asymptotic standard deviations were estimated by maximum likelihood. The order of the processes, and the influence of environmental covariates, were assessed by the likelihood ratio statistic, which is asymptotically $\chi^{2}$-distributed with the number of degrees of freedom equal to the difference in the number of parameters between the models. The influence of environmental covariates was tested after estimating the order of the salp abundance process, within the periods of occurrence of blooms.

Missing data is one of the typical problems of ecological time series. Here, an observation at time $t$ is used only if previous observations are available, considering the order of the model and the time lag (Korn \& Whittemore 1979).

Autocorrelation functions (Anderson 1971) were estimated using Spearman's rank correlation coefficient (Conover 1980).

\section{RESULTS}

\section{Overview of salp time series}

The observed series of aggregate zooid abundance are presented in Fig. 1. For both species, the salient features are year-to-year variability, and seasonality concerning the periods of high salp density. The periods of absence of the species were mainly observed during late summer and winter.

Here, we define a bloom as a period of high salp density (Class 3 and above), lasting at least $2 \mathrm{wk}$. During 
a

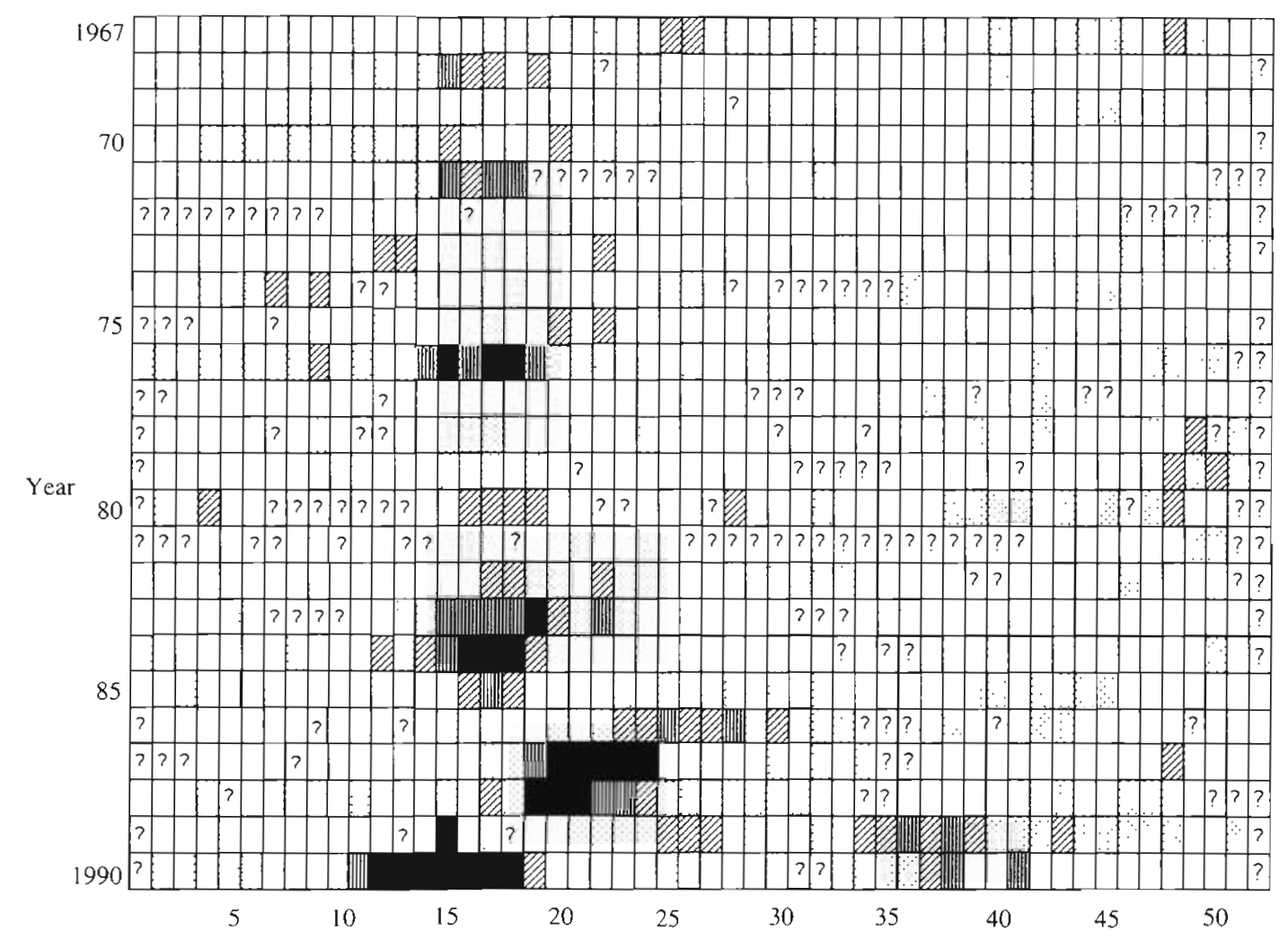

b

2 Missing value

1967

$\triangle$ Class 1

$\square$ Class 2

Class 3

indill Class 4

Classes 5108

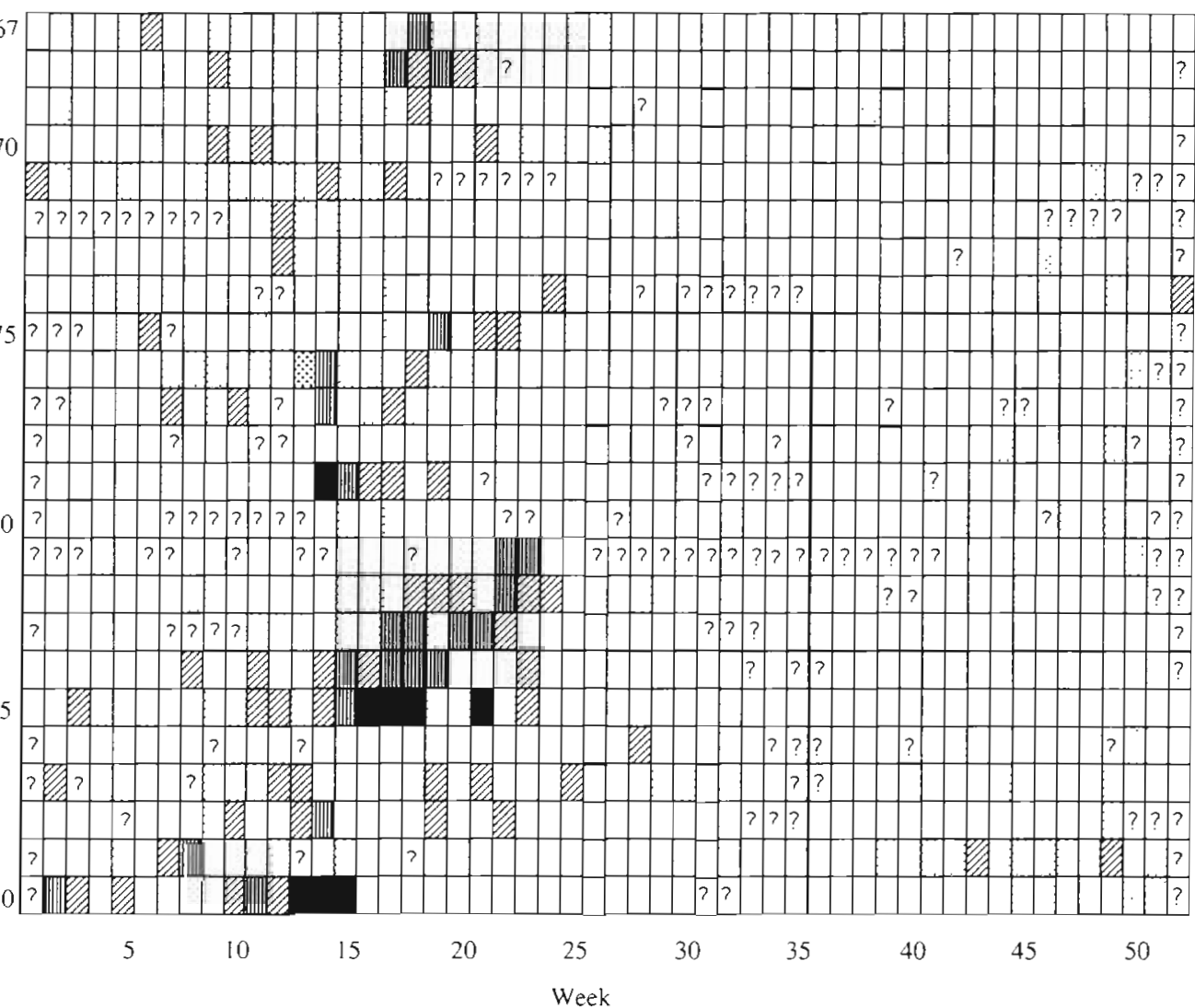

Fig. 1 (a) Thalıa democratica and (b) Salpa fusiformis. Weekly recordings of categoncal abundance of sexual phases (aggregate zoolds) from 1967 to 1990 Abundance Classes 5 to 8 were combined to form a single class 

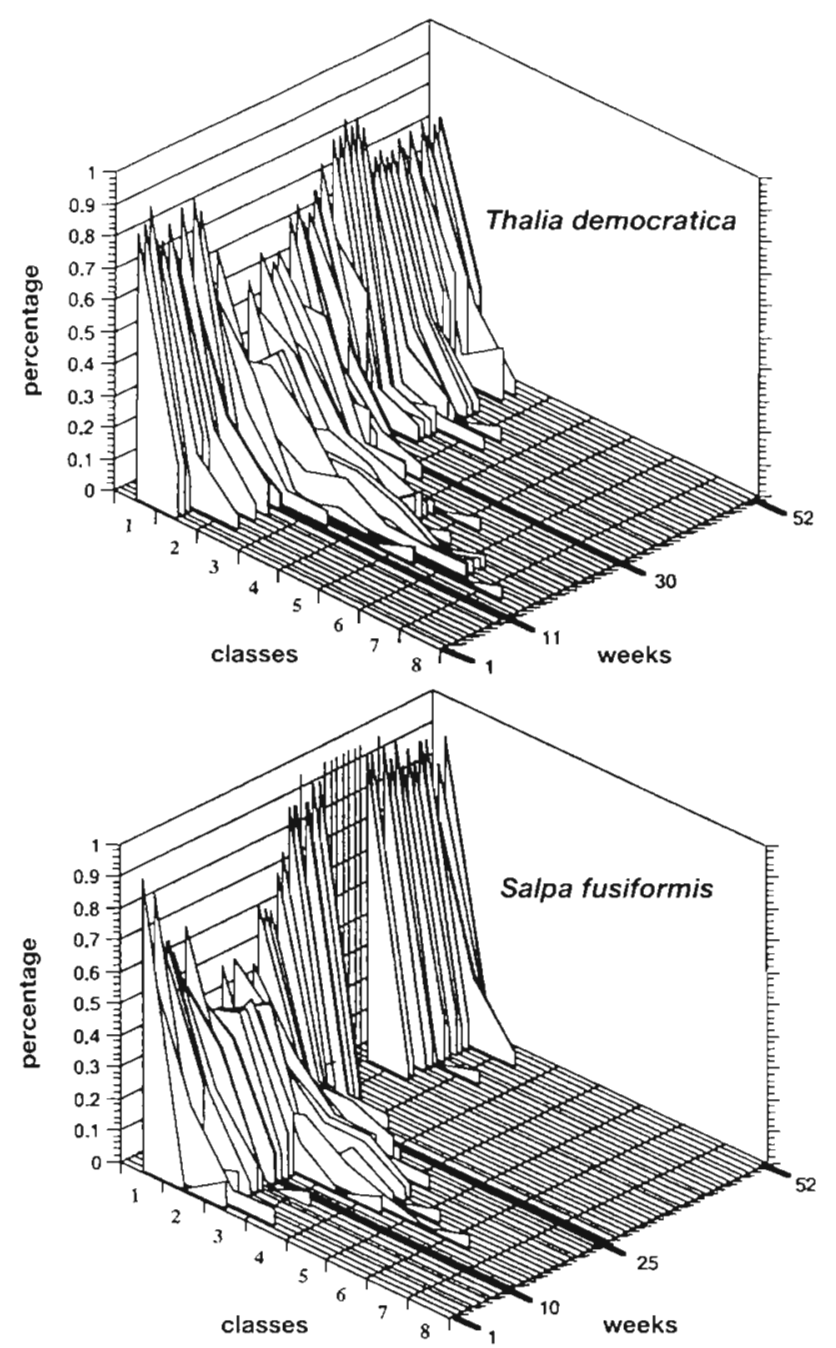

Fig. 2. Thalia democratica and Salpa fusiformis. Percent numbers of observations for each abundance class, as a function of time (week) of year

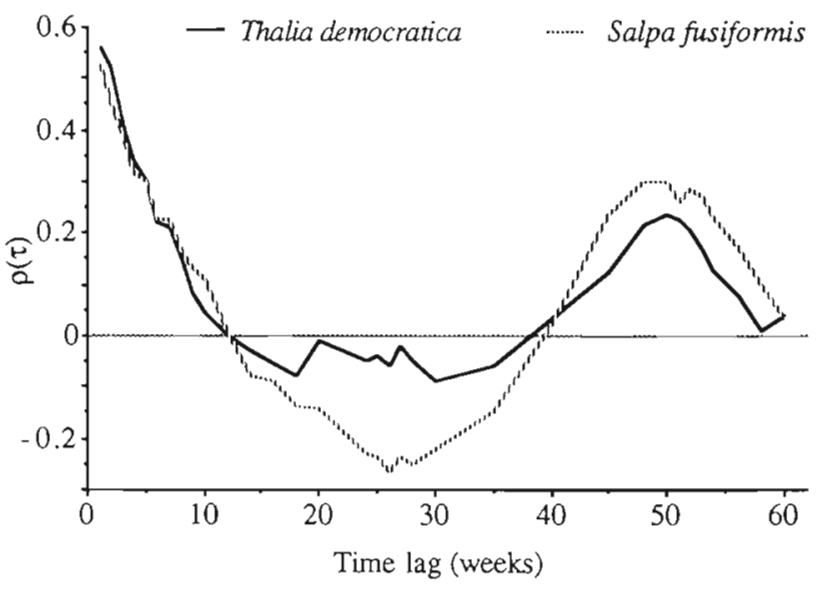

Fig. 3. Thalia democratica and Salpa fusiformis. Spearman rank autocorrelation functions computed from the ordinal time series of abundances winter, the abundance of Thalia democratica remained low, whereas the abundance of Salpa fusiformis may reach Class 3, exceptionally 4, for 1 or 2 wk. Blooms are observed in spring and at the beginning of summer, and may last up to 2 mo. Blooms of $T$. democratica are more frequent and exhibit higher regularity in duration and intensity than those of $S$. fusiformis. Inspection of the salp data in terms of observed frequencies of abundance classes (Fig. 2) shows that blooms occur between Weeks 11 and 30 (mid-March to late July) for T. democratica, and between Weeks 10 and 25 (mid-March to late June) for $S$. fusiformis. These periods are considered below as the periods corresponding to the possible development of blooms. The $T$. democratica series suggests that blooms might have become more frequent and of higher intensity after 1982, and years 1982 to 1985 show a succession of strong and regular blooms of S. fusiformis. Years 1989 and 1990 in the $T$. democratica series are very atypical with respect to the end of summer and autumn: they display sustained high abundance (Class 3 , and 4 wk in Class 4) as opposed to other years of the series. Abundance of $S$. fusiformis was very low during the same period, but this species was present regularly during the end of 1989. S. fusiformis was never observed between Weeks 31 and 37 (August to midSeptember)

Fig. 3 presents the rank autocorrelation functions. The oscillating pattern of these functions is typical of seasonal time series.

\section{Order of salp abundance processes}

Comparison between models with no covariates and of differing order showed that models of order 2 were significantly better than lower-order models $(p<0.01)$, while not significantly different from order 3 models ( $p>0.80$ ). Goodness-of-fit tests for order 2 models (see Appendix) were nonsignificant (Thalia democratica: $\mathrm{p}>$ 0.99; Salpa fusiformis: $\mathrm{p}>0.84$ ). In particular, adding a scale parameter (McCullagh \& Nelder 1989) to the models did not improve the fit. All subsequent analyses were thus performed using models of order 2 .

Tables $2 \& 3$ present the corresponding estimates of parameters with their standard errors and transition probabilities respectively. For brevity, only 25 of the $5^{3}$ probabilities are shown, those corresponding to transition probabilities of the form $\mathrm{P}_{i, i,}$. Concerning Thalia democratica, the maximal estimated probability is to remain in the same class, except for Class 3 , for which the highest probability is to go to Class 2 . If the abundance class is 4 or 5 , the probability of staying in Classes 3 to 5 is above $89 \%$. The conditional probability distributions of Salpa fusiformis show larger disper- 
Table 2. Estimates of parameters (SE in parentheses) corresponding to models of order 2 with no covariates, as defined in the text. Parameters $\lambda, \beta$ and $\alpha$ are defined in the Appendix

\begin{tabular}{|ccc|}
\hline & Thalia democratica & Salpa fusiformis \\
\hline Intercept parameters & \\
$\lambda_{1}$ & $-5.39(0.59)$ & $-3.65(0.99)$ \\
$\lambda_{2}$ & $-3.28(0.56)$ & $-2.19(0.98)$ \\
$\lambda_{3}$ & $-1.74(0.52)$ & $-0.87(0.97)$ \\
$\lambda_{4}$ & $-0.33(0.47)$ & $0.68(0.94)$ \\
Regression coefficients at $t-1$ & \\
$\beta_{1}$ & $-6.40(0.79)$ & $-4.50(0.93)$ \\
$\beta_{2}$ & $-5.05(0.77)$ & $-2.98(0.92)$ \\
$\beta_{3}$ & $-4.03(0.75)$ & $-2.90(0.94)$ \\
$\beta_{4}$ & $-1.93(0.71)$ & $-2.01(0.96)$ \\
Regression coefficients at $t-2$ & \\
$\alpha_{1}$ & $-0.34(0.65)$ & $-0.67(0.79)$ \\
$\alpha_{2}$ & $0.55(0.64)$ & $0.39(0.79)$ \\
$\alpha_{3}$ & $0.66(0.66)$ & $0.09(0.81)$ \\
$\alpha_{4}$ & $0.77(0.66)$ & $0.51(0.86)$ \\
\hline
\end{tabular}

Table 3. Estimated transition probabilities $\mathrm{P}_{1,1,} \mathrm{P}_{i, j, j}$ is the probability that salp abundance is in Class $j$ at time $t$ given it was in Class $i$ at times $t-1$ and $t-2$. These probabilities were computed using models of order 2 with no covariates, as defined in the text

\begin{tabular}{|c|c|c|c|c|c|c|}
\hline & & \multicolumn{5}{|c|}{ Estimated probabilities } \\
\hline \multicolumn{7}{|c|}{ Thalia democratica } \\
\hline & & 1 & 2 & 3 & 4 & 5 \\
\hline & 1 & 0.794 & 0.176 & 0.024 & 0.005 & 0.001 \\
\hline & 2 & 0.292 & 0.480 & 0.168 & 0.045 & 0.015 \\
\hline \multirow[t]{3}{*}{$i$} & 3 & 0.118 & 0.406 & 0.313 & 0.117 & 0.046 \\
\hline & 4 & 0.014 & 0.093 & 0.250 & 0.338 & 0.305 \\
\hline & 5 & 0.005 & 0.032 & 0.112 & 0.268 & 0.583 \\
\hline \multicolumn{7}{|c|}{ Salpa fusiformis } \\
\hline & & 1 & 2 & 3 & 4 & 5 \\
\hline \multirow{5}{*}{$i$} & 1 & 0.820 & 0.132 & 0.035 & 0.010 & 0.003 \\
\hline & 2 & 0.257 & 0.342 & 0.248 & 0.116 & 0.037 \\
\hline & 3 & 0.302 & 0.350 & 0.223 & 0.096 & 0.029 \\
\hline & 4 & 0.105 & 0.231 & 0.317 & 0.246 & 0.101 \\
\hline & 5 & 0.025 & 0.075 & 0.194 & 0.370 & 0.336 \\
\hline
\end{tabular}

Seawater density at $10 \mathrm{~m}\left(\mathrm{~kg} \mathrm{~m}^{-3}\right)$

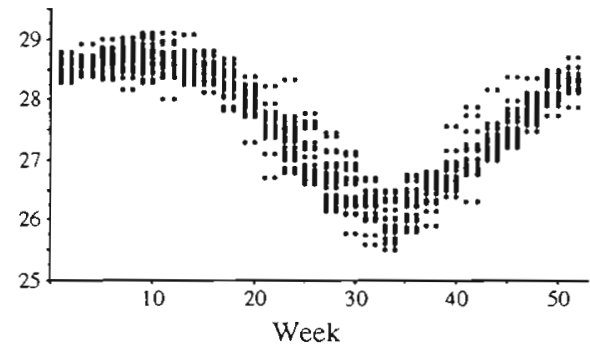

Seawater density at $50 \mathrm{~m}\left(\mathrm{~kg} \mathrm{~m}^{-3}\right)$

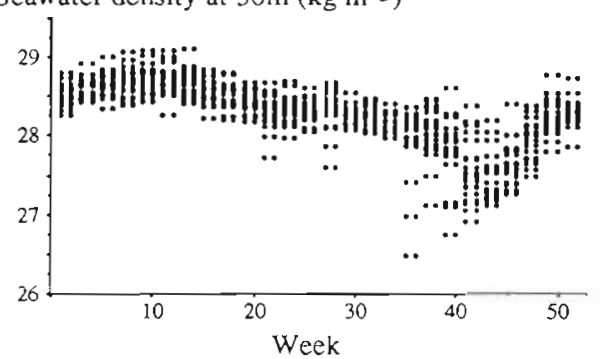

Stability index of the water column $\left(\mathrm{kg} \mathrm{m}^{-3}\right)$

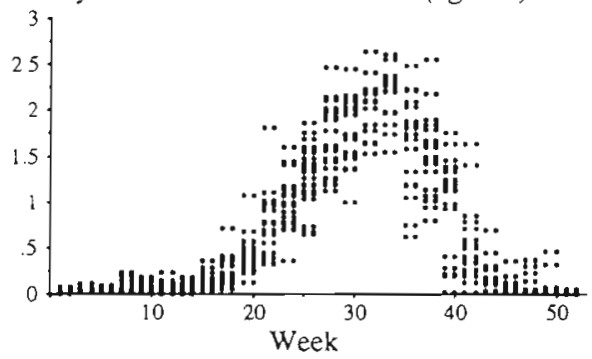

Air temperacure $\left({ }^{\circ} \mathrm{C}\right)$

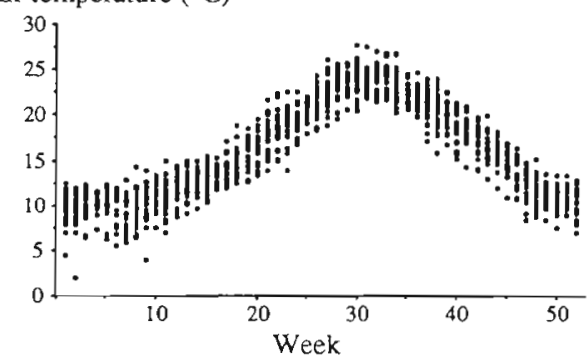

Irradiance $\left(\mathrm{J} \mathrm{cm}^{-2}\right)$

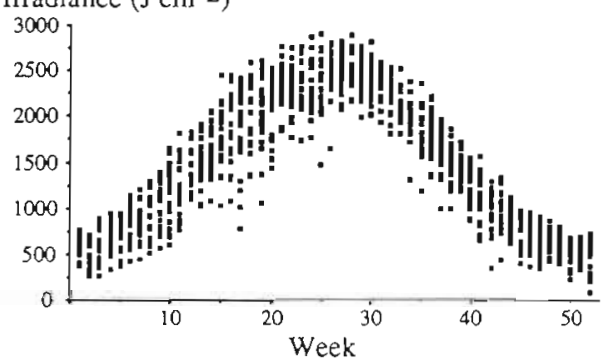

Index of mean wind $\left(\mathrm{m}^{2} \mathrm{~s}^{-2}\right)$

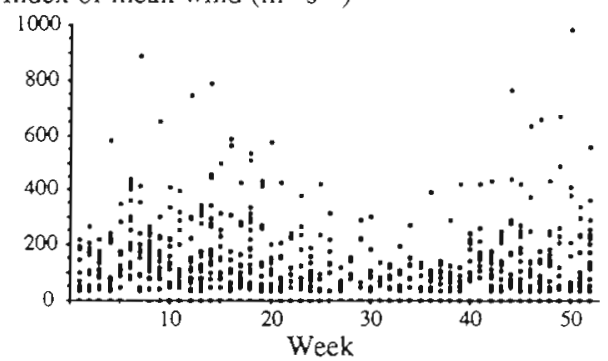

Fiq. 4. Values of seawater density at 10 and $50 \mathrm{~m}(\mathrm{~kg}$ $\left.\mathrm{m}^{-\hat{3}}\right)$, stability index of the water column (differences between seawater densities at 50 and $10 \mathrm{~m}$, in $\mathrm{kg}$ $\mathrm{m}^{-3}$ ), air temperature $\left({ }^{\circ} \mathrm{C}\right)$, irradiance $\left(\mathrm{J} \mathrm{cm}^{-2}\right)$ and index of mean wind $\left(\mathrm{m}^{2}\right.$ $\mathrm{s}^{-2}$ ) versus time (in weeks) from 1967 to 1990 
Salpa fusiformis
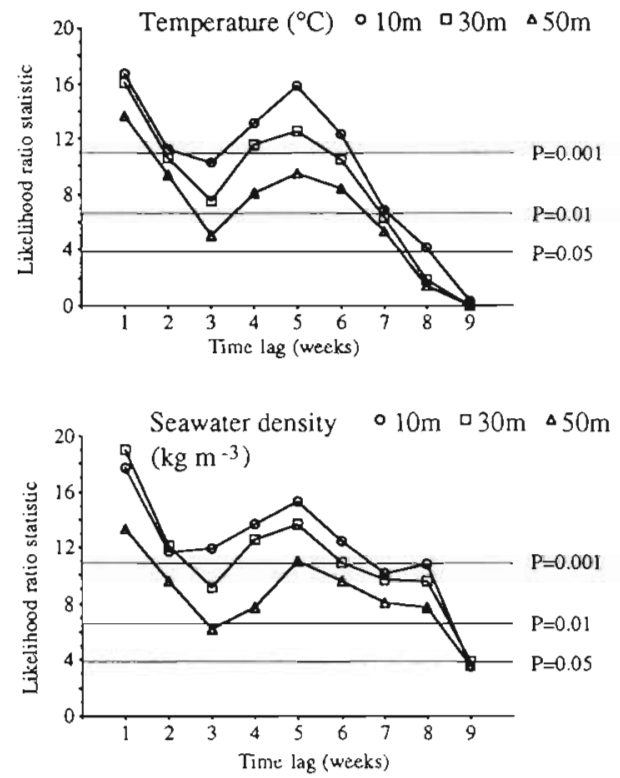

Fig. 5. Salpa fusiformis and Thalia democratica. Values of the likelihood ratio statistic for testing the influence of several hydrological covariates at time lags of 1 to 9 wk. Horizontal lines indicate significance levels based on the $\chi^{2}$-distribution with 1 degree of freedom

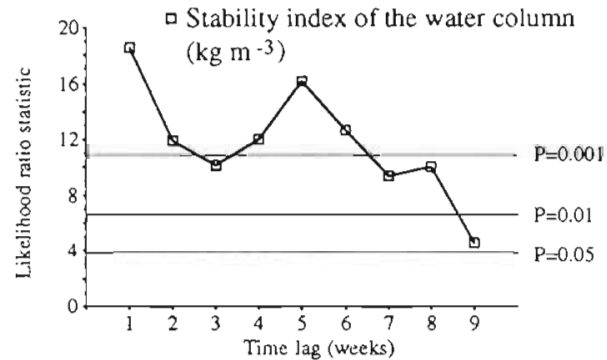

Thalia democratica
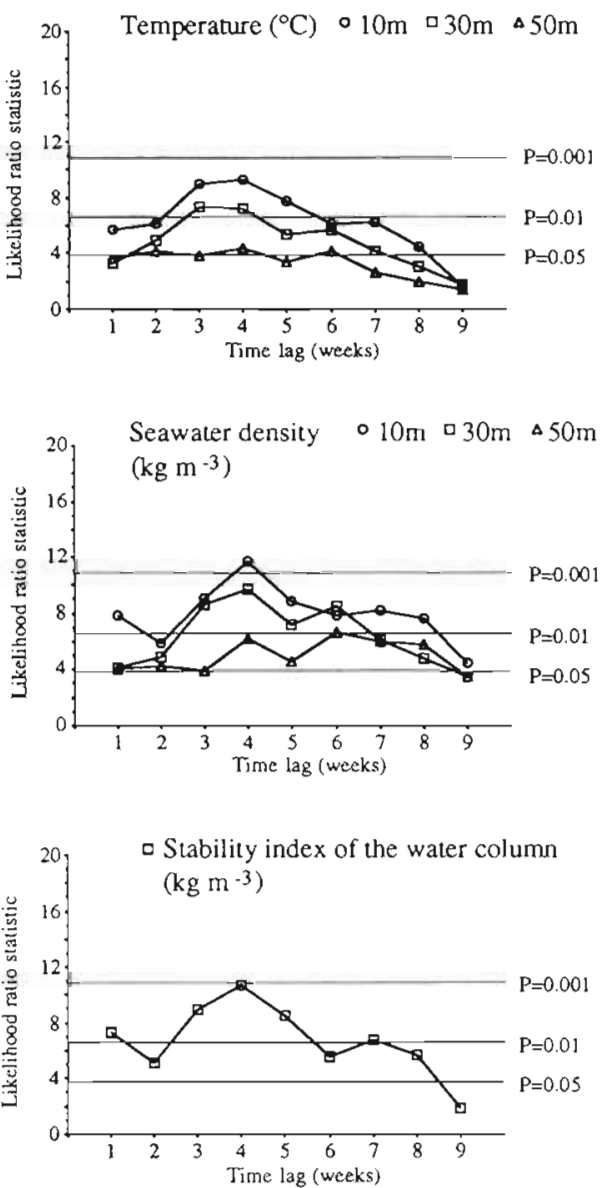

sion than those of $T$. democratica. For instance, when Class 2 is reached, the probability of jumping to abundance Class 3 to 5 is higher than with $T$. democratica $(40.1 \%$ versus $22.8 \%)$. The chances of changing to Class 1 or 2 are always very high, even if the salp density corresponds to abundance Class 4 or 5 . On, and after, reaching Class 3 , the highest probabilities are always to return to a lower class. This reflects the fact that blooms of $T$. democratica are more regular and pronounced than those of $S$. fusiformis.

\section{Influence of environmental variables}

Fig. 4 shows the observed values of several environmental variables from 1967 to 1990 .

Environmental covariates with a time lag $(\tau)$ of from 1 to 9 wk were assessed one by one, within the periods of occurrence of blooms. For hydrological variables, we have selected temperatures and seawater densities recorded at 10,30 and $50 \mathrm{~m}$, densities being computed from temperature and salinity. We also considered the difference between seawater densities at 50 and $10 \mathrm{~m}$ as an index of the vertical stability of the water column.

Figs. $5 \& 6$ illustrate the magnitude of the influence of hydrological and meteorological variables respectively by representing the values of the likelihood ratio statistics as functions of the time lag, for lags of 1 to $9 \mathrm{wk}$.

Hydrological covariates (Fig. 5): hydrological variables have greater influence on Salpa fusiformis than on Thalia democratica. Variables recorded in the upper layers of the water column exert the most significant impact. This was confirmed by the results obtained at other depths $(0,20$ and $75 \mathrm{~m})$, which are not presented here. For $T$. democratica, temperature at $50 \mathrm{~m}$ is rarely significant, and seawater density at $50 \mathrm{~m}$ gives significance levels of $p \approx 0.05$ only. The curves for the 2 species are very similar, whatever the covariate. Significance levels for $S$. fusiformis remain high $(p<$ 0.001 ) at time lags from 1 to $6 \mathrm{wk}$, with 2 peaks at $\tau=1$ and $\tau=5$. In the case of $T$. democratica, lags of 3,4 and 5 wk appear to be the most informative. The likelihood ratio statistics decrease rapidly at greater lags, and the influence of most covariates is nonsignificant at $\tau=9$. 

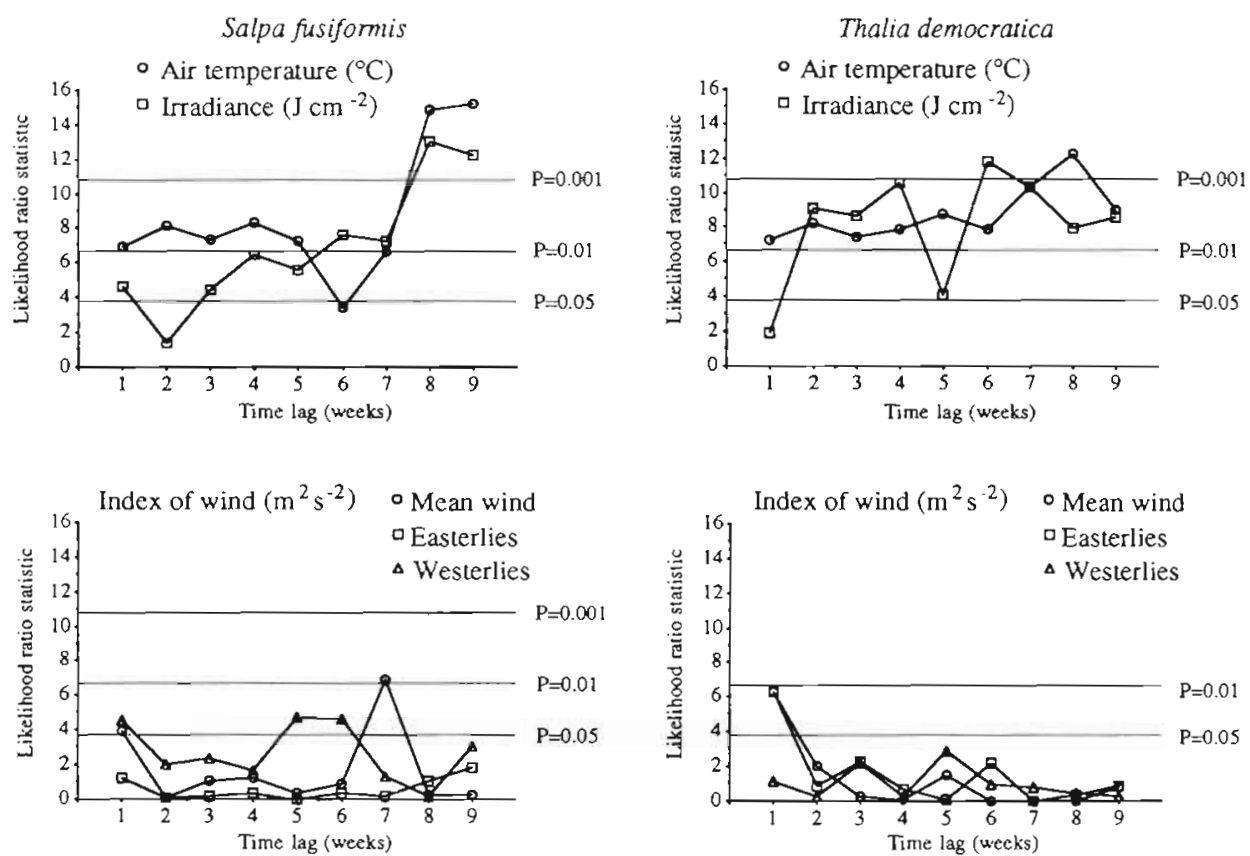

Fig. 6. Salpa fusiformis and Thalia democratica. Values of the likelihood ratio statistic for testing the influence of meteorological covariates at time lags of 1 to $9 \mathrm{wk}$. Horizontal lines indicate significance levels based on the $\chi^{2}$-distribution with 1 degree of freedom
Meteorological covariates (Fig. 6): air temperature and irradiance are almost always influential, with high significance levels at $\tau=8$ and $\tau=9$ for Salpa fusiformis. Mean wind stress index is significant for both species at a time lag of $1 \mathrm{wk}$, and also at $\tau=7(\mathrm{p}<0.01)$ for $S$. fusiformis. Depending on the direction, maximum wind indexes exert different influences on the 2 species. Westerly winds are significant for $S$. fusiformis only, at $\tau=1,5$ and $6(p<0.05)$. In contrast, easterly winds exert a significant influence on Thalia democratica only ( $\mathrm{p}<0.05)$, at a lag of $1 \mathrm{wk}$.

Increases in hydrological temperatures, stability index of the water column, air temperature and irradiance were found to lead to decreases in the probability of going to (staying in) a high abundance state (and thus of observing a bloom), and to increases in the probability of terminating a bloom. However, increases in seawater densities, as well as indexes of wind intensity, lead to opposite effects. These relationships were consistently observed to hold at all time lags.

To illustrate how significant hydrological covariates influence the occurrence of blooms, we have computed several transition probabilities as functions of the vertical stability of the water column and of seawater densities, both for a time lag of 1 wk. $P_{2,2,33}(z)$ and $\mathrm{P}_{3,3, \geq 3}(z)$ correspond to the probabilities of initiating and prolonging a bloom respectively. $P_{3,3, \leq 2}(z)=1-$ $P_{3,3, \leq 2}(z)$ has also been represented to illustrate the probability of terminating a bloom. For example, $\mathrm{P}_{2,2, \geq 3}(z)$ is the probability of transition from abundance
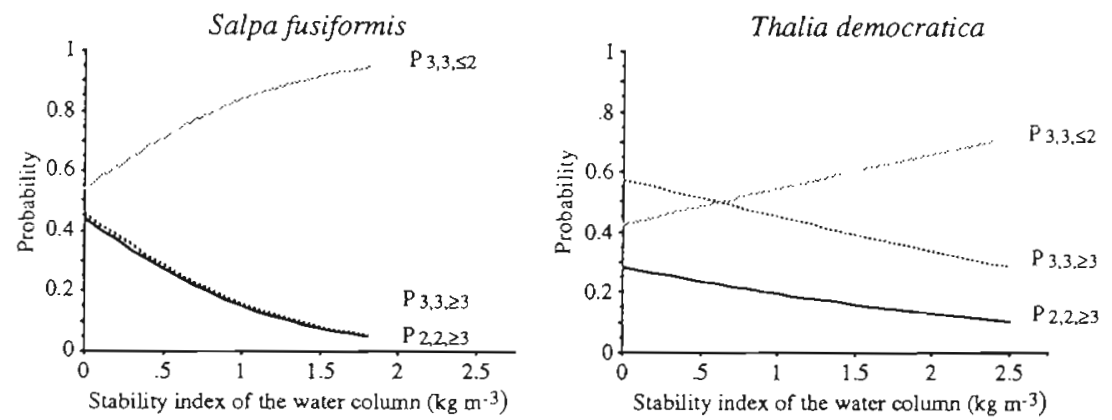

Fig. 7. Salpa fusiformis and Thalia democratica. Influence of stability index of the water column (difference between seawater densities at 50 and $10 \mathrm{~m}$, in $\left.\mathrm{kg} \mathrm{m}^{-3}\right)$ at a time lag of $1 \mathrm{wk}$, on transition probabilities $\mathrm{P}_{2,2, \geq 3}(z), \mathrm{P}_{3,3,3}(z)$ and $\mathrm{P}_{3,3, \leq 2}(z)$. $\mathrm{P}_{2,2, z 3}(z)$ and $P_{3,3,23}(z)$ correspond to probabilities of initiating and prolonging a bloom. $P_{3,3,52}(z)=1-P_{3,3,23}(z)$ represents the probability of terminating a bloom. Probabilities are computed from the parameter estimates in the corresponding models, with stability varied between the extreme values observed during the periods of occurrence of blooms 

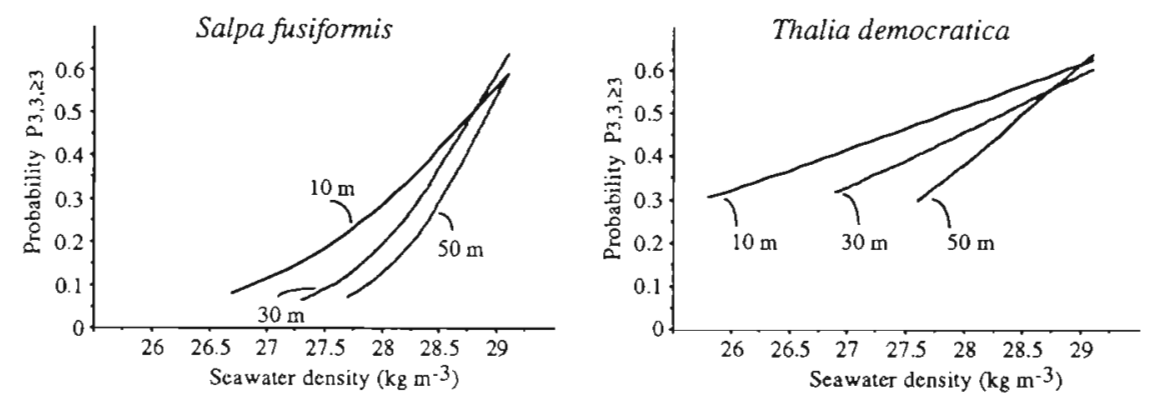

Fig. 8. Salpa fusiformis and Thalia democratica. Influence of seawater densities $\left(\mathrm{kg} \mathrm{m}^{-3}\right)$ at a time lag of 1 wk and at depths of 10,30 and $50 \mathrm{~m}$ on transition probabilities of remaining in a bloom, $\mathrm{P}_{3,3,23}(\mathrm{z})$. Probabilities are computed from the parameter estimates in the corresponding models, with seawater densities varied between the extreme values observed during periods of occurrence of blooms

Class 2 at time $t-2$ and at time $t-1$ to Class 3 or above at time $t$, when the value taken by the covariate of interest is $z$ at $t-1$ (i.e. $\tau=1$ ). Fig. 7 illustrates the influence of the vertical stability of the water column. Stability values give very similar transition probabilities $P_{2,2,23}(z)$ and $P_{3}$, 3. $z_{3}(z)$ for Salpa fusiformis, and the influence on transition probabilities is stronger for this species: increasing stratification levels lead to sharp reductions in probabilities $P_{2,2,23}(z)$ and $P_{3,3,23}(z)$ of observing a bloom, and to sharp increases in the probability $P_{3,3, \leq 2}(z)$ of terminating a bloom. Moreover, ranges of variation of the transition probabilities are wider for this species than for Thalia democratica. For the latter, the probability of remaining in a high abundance class, $\mathrm{P}_{3,3,23}(z)$, is about $30 \%$ even at the highest observed value of vertical stability. Similar results are observed at various time lags: the earlier in the season the stratification of the water column occurs, the lower the probability of observing a bloom and the higher the probability of terminating a bloom. Fig. 8 illustrates the influence of seawater densities at 3 depths $(10,30$ and $50 \mathrm{~m})$, which is again stronger for $S$. fusiformis: low densities lead to lower transition probabilities $\mathrm{P}_{3,3,23}(z)$ of remaining in a high abundance class ( 3 or above), and the range of variation is always larger than for $T$. democratica. At greater depths, the range of observed variation in density is narrower but the rate of change of the transition probability as a function of the variable is higher. Temperatures exert the opposite influence.

Fig. 9 presents 2 observed trajectories of mean wind index, from Weeks 9 to 29 of 1968 and 1983. Transition probabilities of remaining in a bloom, $\mathrm{P}_{3,3, \geq 3}(z)$ have been computed for both species, using values of these trajectories at a time lag of $1 \mathrm{wk}$ and the parameter estimates in the corresponding models. Gusts of wind lead to sudden jumps in transition probabilities. $\mathrm{Ob}$ served abundance categories are also illustrated in the figure. 1968 is characterised by 2 peaks of mean wind velocity. A bloom of Thalia democratica starts at the first peak, while high densities of Salpa fusiformis coincide better with the second peak. 1983 sees a succession of decreasing strong winds from Week 15 to 20. High abundance classes of $T$. democratica were observed concomitantly, while $S$. fusiformis was abundant from the middle of the strong wind period. Blooms of both species in that year lasted until Week 22, although mean wind index was very low. However, transition probabilities of remaining in a bloom were still as high as $35 \%$ for $S$. fusiformis and $45 \%$ for $T$. democratica.

\section{DISCUSSION}

We have studied the occurrences of blooms of 2 salp populations, from two 24 yr time series of semiquantitative abundance recordings of the aggregate zooids of both species. The aim was to assess the relationship between influential environmental variables and bloom development.

Four characteristics of the sampling scheme may have conditioned our results: use of the Juday Bogorov net; sampling at a fixed station; pooling all samples from a given week; and semiquantitative determination of abundance.

Salps are distributed in swarms, so they are usually sampled obliquely or horizontally with larger nets. The use of the Juday Bogorov net may thus have affected the precision of salp density determination, because of smaller filtered volumes of water. However, on several occasions, salps were concomitantly sampled with a Regent net (diameter $1 \mathrm{~m}$ ), or an Omori net (diameter $1.5 \mathrm{~m}$ ) (Braconnot 1971, Choe 1985, Braconnot et al. 1990). Abundances estimated from the different nets were of similar magnitude, and never differed by more than 1 abundance class.

During the spring of 1983, Nival et al. (1990) sampled salp populations with a net of the same diameter as the 

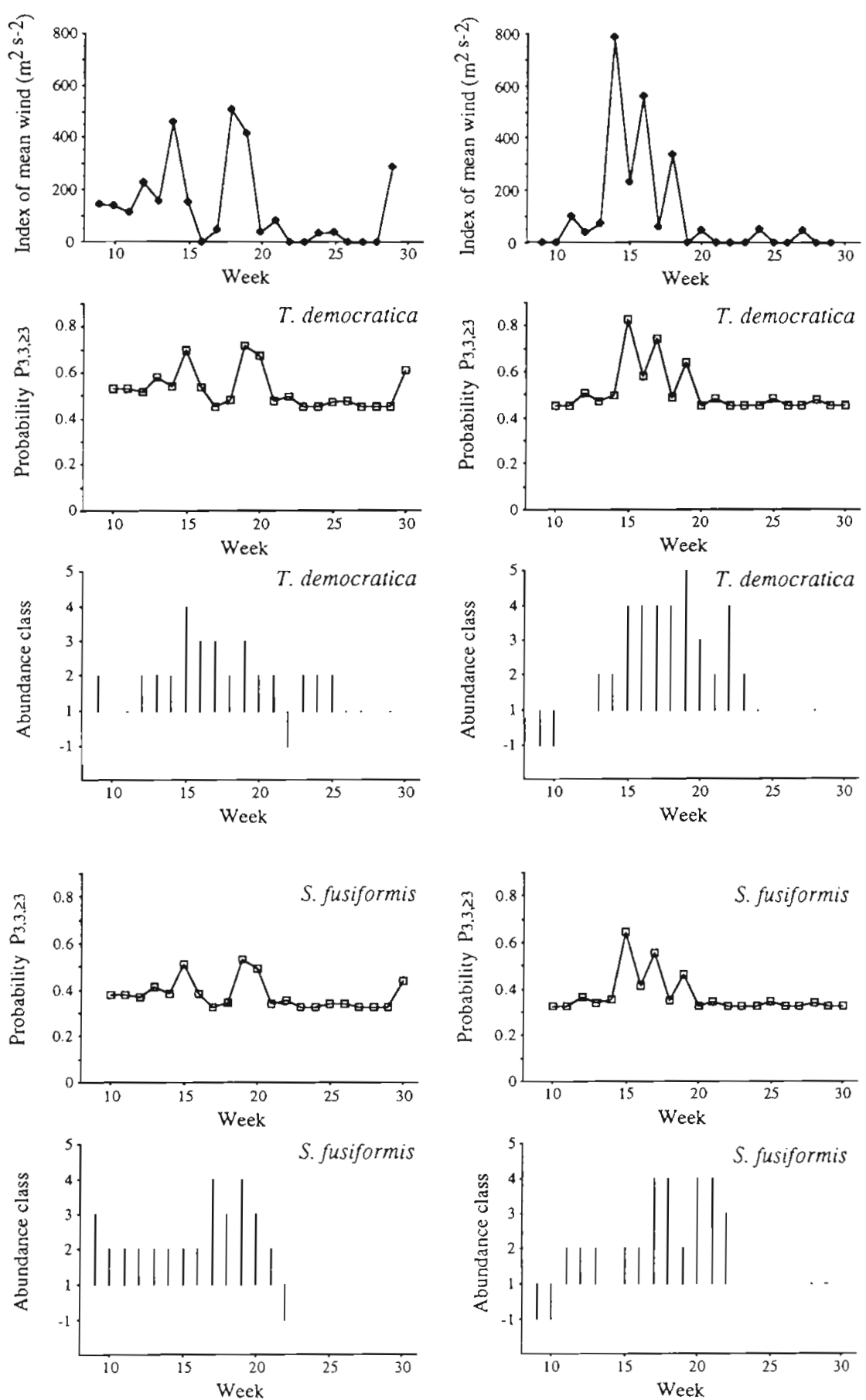

Fig. 9. Salpa fusiformis and Thalia democratica. Observed trajectories of mean wind intensity $\left(\mathrm{m}^{2} \mathrm{~s}^{-2}\right)$, from Weeks 9 to 29 of 1968 (left) and 1983 (right), and transition probabilities of remaining in a bloom, $P_{3,3, z 3}(z)$. These probabilities have been computed using observed values of mean wind index at a time lag of $1 \mathrm{wk}$ and the parameter estimates in the corresponding models. The observed abundance classes for the 2 species are also represented in bar chart form (missing values are coded as -1 )

1968

1983

Juday Bogorov: several vertical hauls from a depth of $200 \mathrm{~m}$ to the sea surface were taken at different stations in the coastal and offshore waters of the Ligurian Sea, and quantitative enumeration was carried out. The results showed that high abundances of aggregate zooids of Salpa fusiformis are not localised but spread out over a distance of at least 18 miles towards the open sea. The variations in the estimated densities between stations never exceeded a factor of 4 , which corresponds to the mean distance between adjacent abundance classes. As for Thalia democratica, this species was mainly present near the coast.

Finally, considering also their growth rates and generation times (Heron 1972, Braconnot \& Jégu 1981, Braconnot et al. 1988), the weekly time step seems well adapted to the monitoring of these species, as the time 
scale of the fluctuations in aggregate zooid populations is of the same order of magnitude. This is confirmed in the present series by the dependence between successive observations, clearly visible in Fig. 1.

These observations suggest that blooms are well detected under the sampling conditions of the present study.

The model used here was specifically designed to take account of the above characteristic features of the observed series, i.e. the ordinal nature and the seasonal pattern of the data, the dependence between observations taken at neighbouring time points, and the wish to evaluate the influence of exogenous covariates. The usefulness of stochastic models for the analysis of time series is based principally on their ability to account for both variability in and dependence between successive observations, with a relatively small number of parameters. The limited number of parameters in the model allows their estimation from field data, and also the testing of hypotheses. On the other hand, we did not attempt here to model explicitly the life history of salps. While the Markov chain model implicitly links successive generations of aggregate zooids without considering the solitary zooids which produce them, the available data on solitary zooid abundance were not considered reliable, as most solitary zooids in the samples are likely to have been extracted from the body cavity of pregnant aggregate zooids during handling operations. In that sense, our modelling approach at the population level is complementary to the classical differential simulation models of population dynamics (e.g. Andersen \& Nival 1986a), which, as a result of their deterministic nature, include large numbers of parameters, that must of necessity be estimated from laboratory experiments.

Our results suggest that, with respect to their influence on salp abundance, environmental covariates are of 2 main types: wind indexes on the one hand, and hydrological variables, air temperature and irradiance on the other. The influence of the latter covariates determines the period of the year when blooms may occur through the seasonal forcing of the stratification of the water column. The occurrence of blooms at the end of winter or beginning of spring, when sea temperature and stability of the water column increase rapidly, and the density of surface waters decreases, appears to result from several concomitant phenomena. The water column has been well mixed and the amount of nutrients is high in the euphotic area. The warming of surface waters due to an increase in solar irradiance and air temperature tends to stabilise the water column and allows the development of phytoplankton populations. Later in the season, when warming and stratification become more pronounced, phytoplankton production decreases in intensity, resulting in a secondary decrease in abundance of salp populations. Moreover, the increase with temperature of salp excretion rates (Andersen \& Nival 1986b) may also contribute to the decline of salp populations in late spring and summer. Thus, the development of salp populations appears to be affected mainly by the degree of stabilisation of the water column: the probability that salp populations reach a high density, or stay at a high abundance level for several weeks, breaks down with the seasonal increase of temperature and the vertical stratification of the upper layer.

In contrast, indexes of wind intensity are highly variable, and only short-term responses of salp populations to the effect of wind intensity are discussed here. The significance at time lags greater than $1 \mathrm{wk}$ may be artifactual or may be linked to periodic atmospheric depressions during winter and spring. Gusts of wind favour the development of salp populations. The stress of the wind on the ocean surface is transmitted downwards by turbulent motion. A pumping effect on nutrients through the thermocline may result (Klein \& Coste 1984), favouring the new production of phytoplankton. Because of their high growth rates, salp populations then have a demographic advantage that enables them to supplant other herbivorous species such as copepods and appendicularians. However, with respect to their directions, strong winds do not have the same impact on the abundances of the 2 species. Westerly wind intensity was significant for Salpa fusiformis, and easterly wind for Thalia democratica. This shows the influence of hydrodynamic circulation on the populations, which do not have the same distribution. Westerly winds lead to local upwelling, while easterly winds involve a process of surface waters accumulating near the coast. Bougis (1968) described the relationships between gusts of westerly wind and the emergence of $S$. fusiformis during summer. We confirm this observation, which shows that this species is found principally in the open sea. In fact, $S$. fusiformis is imported to the coast from the near open sea, where it has been observed at depths up to $700 \mathrm{~m}$ (Gorsky et al. 1991, Laval et al. 1992). On the contrary, $T$. democratica, whose blooms are more pronounced and regular in our series, appears to be restricted to the coastal zone (Nival et al. 1990). Moreover, this species is more strongly affected by surface hydrological variables, while $S$. fusiformis is influenced by values at a wide range of depths. $T$. democratica thus appears to be a near-surface species. Similarly, the increasing abundance of Thaliacea (Paffenhöfer \& Lee 1987) and of Appendicularia (Taggart \& Frank 1987) observed in coastal zones has also 
been interpreted as a result of wind-driven shoreward advection of water.

Our methodology allowed the identification of hydrodynamical processes that modulate the dynamics of salp populations in the coastal waters of the Western Mediterranean. Our results shed some light upon the effects of climatic variations on the vertical transport of biogenic material in the ocean. Salp fecal pellets costitute an important fraction of the sestonic organic matter that leaves the euphotic area during spring and beginning of summer, when the vertical flux is highest (data from Mostajir 1992). An early and fast warming of the sea surface temperature does not favour salp population development, and thus the export to the bottom of the organic matter photosynthetised in surface waters. An opposite effect may be observed during cold or disturbed years, with strong and repeated gusts of wind, occurring during the period of stratification of the water column.

Acknowledgements. We thank anonymous referees for their constructive comments on an earlier version of the manuscript. Valérie Andersen, Jacqueline Goy and Paul Nival have greatly contributed to improve this work by their critical approach to the statistical model presentation and helpful suggestions on the examples and discussion.

\section{APPENDIX}

An observed salp series is considered as a particular realisation of a stochastic process in discrete time $\boldsymbol{Y}=\left(Y_{t}\right)_{t \geq 1}$, where $t$ is time of observation. $Y_{1}$ takes its values in the set $E=\{1, \ldots, 5\}$ of the ordered categories used to characterise salp abundance. Concomitantly with the process $Y$, a stochastic environmental process $Z=\left(Z_{t}\right)_{t z t}$ is observed, which corresponds to the covariates of interest.

The model is written in terms of the cumulative probability function of the salp abundance process $Y_{1}$ conditional on the observed past. The cumulative probabilities are a function of a linear combination of the previous abundance states of salps (the number of previous states determines the order of the saip process), and the exogenous covariates taken at previous times. The logistic form of McCullagh's generalised linear model for ordered categorical outcomes (McCullagh 1980) has been chosen. It is a strictly increasing function between 0 and 1 .

Suppose the order of the process is 2 , and the time lag for the exogenous covariates is $\tau(\tau>0)$. For $k, i, j \in E$, the probability distribution (Pr) of $Y_{t}$, conditional on the whole past, is written:

$$
\operatorname{Pr}\left(Y_{t} \leq j \mid Y_{i-1}, Y_{t-2} \ldots, Y_{1} ; Z_{t-1}, Z_{t-2} \ldots, Z_{1}\right)=\operatorname{Pr}\left(Y_{t} \leq j \mid Y_{t-1}=i, Y_{i-2}=k ; Z_{t-\tau}=z\right)=f\left[\lambda,-\beta_{3} I_{3}(t-1)-\alpha_{k} I_{k}(t-2)-\gamma Z\right]
$$

where $f(x)=\mathrm{e}^{x} /\left(1+\mathrm{e}^{x}\right)$ is the logistic function, and the $\lambda \mathrm{s}, \beta \mathrm{s}, \alpha \mathrm{s}$ and $\gamma$ are the unknown parameters to be estimated. The $\lambda$ s are called the intercept parameters. The $\beta$ s and $\alpha$ s are the regression coefficients on the previous abundance states at $t-1$ and $t-2$, which are represented by the indicator vanables $I_{i}(t-1)$ and $I_{k}(t-2)$ respectively. For instance, $I_{j}(t-1)=1$ if abundance class is $i$ at time $t-1,0$ otherwise. $\gamma$ is the regression coefficient on the environmental covariate taken at $t-\tau$. The parameters to be estimated are thus: $\left(\lambda_{1}, \lambda_{2}, \lambda_{3}, \lambda_{4}\right),\left(\beta_{1}, \beta_{2}, \beta_{3}, \beta_{4}\right),\left(\alpha_{1}, \alpha_{2}, \alpha_{3}, \alpha_{4}\right)$ and $\gamma$.

The corresponding transition probability is computed in terms of a difference:

$$
\operatorname{Pr}\left(Y_{t}=j \mid Y_{t-1}=i, Y_{t-2}=k_{i} Z_{t-i}=z\right)=\operatorname{Pr}\left(Y_{t} \leq j \mid Y_{t-1}=i, Y_{t-2}=k_{i} Z_{i-\tau}=z\right)-\operatorname{Pr}\left(Y_{t} \leq j-1 \mid Y_{t-1}=i, Y_{t-2}=k_{i} Z_{t-t}=z\right)
$$

for $1 \leq j \leq 5$, and

$$
\begin{array}{l|l}
\operatorname{Pr}\left(Y_{1} \leq 0\right. & \left.Y_{t-1}=i, Y_{t-2}=k_{i} Z_{t-1}=z\right)=0 \\
\operatorname{Pr}\left(Y_{t} \leq 5\right. & \left.Y_{t-1}=i, Y_{t-2}=k_{i} Z_{t-1}=z\right)=1
\end{array}
$$

The $\log$-likelihood $l$ is written:

$$
I=\sum \log \left[\operatorname{Pr}\left(Y_{t}=j \mid Y_{t-1}=j_{1} Y_{t-2}=k_{i} Z_{t-1}=Z\right)\right]
$$

where the sum is computed over weeks corresponding to periods of blooms, and over all the vears of the series. The likelihood ratio statistic is asymptotically $\chi^{2}$-distributed with the number of degrees of freedom equal to the difference of the number of parameters between the nested models. Ménard et al. (1993) have shown that maximum likelihood estimators and likelihood ratio tests possess the desired asymptotic properties. The model and parameters and their asymptotic covariance matrix were estimated with a modified Raphson-Newton algorithm (IMSL 1987).

While no formal statistical procedure seems available to test the goodness-of-fit of models including continuous covariates, a possible goodness-of-fit test of models with no covariates is based on the statistic of Anderson \& Goodman (1957):

$$
D=-2\left[1-\sum_{k} \sum_{1} \sum_{1} n_{k, j} \log \left(n_{k, 1} / n_{k,+}\right)\right]
$$

where $n_{k}$, is the number of transitions from $k$ at Week $t-2$ and $i$ at Week $t-1$ to $j$ at Week $t$, and + indicates summation over the subscript.

$D$ is asymptotically $\chi^{2}$-distributed with the number of degrees of freedom equal to the difference of the number of parameters between the models. 


\section{LITERATURE CITED}

Andersen, V. (1985). Filtration and ingestion rates of Salpa fusiformis Cuvier (Tunicata: Thaliacea): effect of size, individual weight and algal concentration. J. exp. mar. Biol. Ecol. 87: 13-29

Andersen, V., Nival, P. (1986a). A model of the population dynamics of salps in coastal waters of the Ligurian Sea. J. Plankton Res. 8: 1091-1110

Andersen, V., Nival, P. (1986b). Ammonia excretion rate of Salpa fusiformis Cuvier (Tunicata: Thaliacea): effects of individual weight and temperature. J. exp. mar. Biol. Ecol. 99: $121-132$

Anderson, T. W. (1971). The statistical analysis of time series. Wiley, New York

Anderson, T. W., Goodman, L. A. (1957). Statistical inference about Markov chains. Ann. Math. Stat. 28: 89-110

Atkinson, L. P., Paffenhöfer, G. A., Dunstan, W. M. (1978). The chemical and biological effect of a gulf stream intrusion off St. Augustine, Florida. Bull. mar. Sci. 28: 667-679

Berner, L. (1967). Distributional atlas of Thaliacea in the California Current region. CalCOFI Atlas 8

Bougis, P. (1968). Le problème des remontées d'eaux profondes à Villefranche-sur-Mer. Cah. océanogr. 20: $597-603$

Box, G. E. P., Jenkins, G. M. (1976). Time series analysis: forecasting and control, Revised edn. Holden-Day, Oakland, $\mathrm{CA}$

Braconnot, J. C. (1963). Etude du cycle annuel des salpes et dolioles en rade de Villefranche-sur-Mer J. Cons. perm. int. Explor. Mer 28: 21-36

Braconnot, J. C. (1971). Contribution à l'étude biologique et écologique des tuniciers pélagiques salpides et doliolides. I. Hydrologie et écologie des salpides. Vie Milieu 22: $257-286$

Braconnot, J. C., Choe, S.M., Nival, P. (1988). La croissance et le développement de Salpa fusiformis. Annls Inst. Océanogr., Paris 64: 101-114

Braconnot, J. C., Etienne, M., Moitié, M. (1990). Distribution du tunicier pélagique Salpa fusiformis, Cuvier à Villefranche: 13 années d'observations. Rapp. Comm. int. Mer Médit. 32: 225

Braconnot, J. C., Jégu, M. (1981). Le cycle de Thalia democratica (Salpidae). Croissance et durée de chaque génération. Rapp. Comm. int. Mer Médit. 27: 197-198

Brattström, H. (1972). On Salpa fusiformis Cuvier (Thaliacea) in Norwegian coastal and offshore waters. Sarsia 48 : $71-90$

Caron, D. A., Madin, L. P., Cole, J. J. (1989). Composition and degradation of salp fecal pellets: implications for vertical flux in oceanic environments. J. mar. Res. 47: 829-850

Choe, S. M. (1985). Contribution à l'étude biologique et écologique des tuniciers pélagiques salpides en mer Ligure. Thèse de Doctorat $3^{\text {e }}$ Cycle, Université Paris 6

Conover, W. J. (1980). Practical nonparametrics statistics, 2nd edn. Wiley, New York

Deibel, D. (1982). Laboratory measured grazing and ingestion rates of salp, Thalia democratica Forskal, and the doliolid, Dolioletta gegenbauri Uljanin (Tunicata, Thaliacea). J. Plankton Res. 4: 189-201

Deibel, D. (1985). Blooms of the pelagic tunicate Dolioletta gegenbauri: are they associated with Gulf Stream frontal eddies? J. mar. Res. 43: 211-236

Eston, V. R., Galves, A., Jacobi, C. M., Langevin, R., Tanaka, N. I. (1986). Chthamalus bisinuatus (Cirripedia) and Brachidontes solisianus (Bivalvia) spatial interactions: a stochastic model. Ecol. Modelling 34: 99-113
Etienne, M., Corre, M. C., Dallot, S., Nival, P. (1991). Observations hydrologiques à une station côtière méditerranéenne. Point $B$ - rade de Villefranche-sur-Mer $\left(43^{\circ}\right.$ $41^{\prime} 10^{\prime \prime} \mathrm{N}-07^{\circ} 19^{\prime} 00^{\prime \prime}$ E). Campagnes Océanographiques Françaises 14, IFREMER, Brest

Fraser, J. H. (1962). The role of ctenophores and salps in zooplankton production and standing crop. Rapp. Cons. perm. int. Explor. Mer 153: 121-123

Frontier, S. (1969). Sur une méthode d'analyse faunistique rapide du zooplancton. J. exp. mar. Biol. Ecol. 3: 18-26

Gorsky, G., Lins da Silva, N., Dallot, S., Laval, Ph., Braconnot, J. C., Prieur, L. (1991). Midwater tunicates: are they related to the permanent front of the Ligurian Sea (NW Mediterranean)? Mar. Ecol. Prog. Ser. 74: 195-204

Heron, A. C. (1972). Population ecology of a colonizing species: the pelagic tunicate Thalia democratica. I. Individual growth rate and generation time. Oecologia 10: 269-293

Heron, A. C., Benham, E. E. (1984). Individual growth rates of salps in three populations. J. Plankton Res 6: 811-828

Heron, A. C., Benham, E. E. (1985). Life history parameters as indicators of growth rate in three salp populations. J. Plankton Res. 7: 365-379

IMSL (1987). User's manual: Math/Library (Version 1.0). Fortran subroutines for mathematical applications. ProblemSolving Software Systems. IMSL, Inc. Houston

Klein, P., Coste, B. (1984). Effects of wind-stress variability on nutrient transport into the mixed layer. DeepSea Res. 31: $21-37$

Korn, E. L., Whittemore, A. S. (1979). Methods for analyzing panel studies of acute health effects of air pollution. Biometrics 35: 795-802

Laval, Ph., Braconnot, J. C., Lins da Silva, N. (1992). Deep planktonic filter-feeders found in the aphotic zone with the Cyana submersible in the Ligurian Sea (NW Mediterranean). Mar. Ecol. Prog. Ser. 79: 235-241

Le Borgne, R. (1983). Note sur les proliférations de Thaliacés dans le golfe de Guinée. Océanogr. trop. 18: 49-54

Le Borgne, R., Moll, P. (1986). Growth rates of the salp Thalia democratica in Tikehau Atoll (Tuamoto Is.). Océanogr. trop. 21: 23-29

Madhupratap, M., Devassy, V. P., Sreekumaran Nair, S. R., Rao, T. S. (1980). Swarming of pelagic tunicates associated with phytoplankton bloom in the Bay of Bengal. Indian J. mar. Sci. 9: 69-71

Madin, L. P. (1982). Production, composition and sedimentation of salp fecal pellets in oceanic waters. Mar. Biol 67: 39-45

Madin, L. P., Cetta, C. M. (1984). The use of gut fluorescence to estimate grazing by oceanic salps. J. Plankton Res. 6 : $475-492$

McCullagh, P. (1980). Regression models for ordinal data. J. R Statist. Soc. B 42: 109-142

McCullagh, P., Nelder, J. A. (1989). Generalized linear models, 2nd edn. Chapman and Hall, London

Ménard, F., Dallot, S., Thomas, G. (1993). A stochastic model for ordered categorical time series. Application to planktonic abundance data. Ecol. Modelling 66: 101-112

Morris, R. J., Bone, Q., Head, R., Braconnot, J. C., Nival, P. (1988). Role of salps in the flux of organic matter of the bottom of the Ligurian Sea. Mar. Biol. 97: 237-241

Mostajir, B. (1992). Suivi temporel du flux descendant des pelotes fécales en mer Ligure. Mémoire de DEA d'Océanographie biologique, Université Paris 6

Mullin, M. M. (1983). In situ measurement of filtering rates of the salp Thalia democratica, on phytoplankton and bacteria. J. Plankton Res. 5: 279-288

Munholland, P. L., Kalbfleisch, J. D. (1991). A semi-Markov model for insect life history data. Biometrics 47: 1117-1126 
Nival, P., Braconnot, J. C., Andersen, V., Oberdorff, T., Choe, S. M., Laval, Ph. (1985). Estimation de l'impact des salpes sur le phytoplancton en mer Ligure. Rapp. Comm. int. Mer Médit. 29: 283-286

Nival, P., Braconnot, J. C., Oberdorff, T. (1990). Structure démographique d'une population de salpes en mer Ligure. Mar. Nat. 3: 1-8

Paffenhöfer, G. A., Lee, T N. (1987). Development and persistence of patches of Thaliacea. S. Afr. J. mar. Sci. 5: $305-318$

Priestley, M. B. (1989). Spectral analysis and time series, Vols. 1 \& 2. Academic Press, London

Silver, M. W. (1975). The habitat of Salpa fusiformis in the California Current as defined by indicator assemblages. Limnol. Oceanogr. 20: 230-237

This article was submitted to the editor
Taggart, C. T., Frank, K. I (1987). Coastal upwelling and Oikopleura occurrence ('slub'): a model and potential application to inshore fisheries. Can. J. Fish. Aquat. Sci. 44: $1729-1736$

Thompson, W. A., Vertinsky, I. (1975). Application of Markov chains to analysis of a simulation of bird's foraging. J. theor. Biol. 53: 285-307

Tsuda, A., Nemoto, T. (1992). Distribution and growth of salps in a Kuroshio warm-core ring during summer 1987. Deep Sea Res. 39 (Suppl. 1): S219-S229

Usher, M. B. (1979). Markovian approaches to ecological succession. J. Anim. Ecol. 48: 413-426

Woolhouse, M. E. J., Harmsen, R. (1991). Population dynamics of Aphis pomi: a transition matrix approach. Ecol. Modelling 55: 103-111

Manuscript first received: February 8, 1993

Revised version accepted: October 21, 1993 